\title{
Sarcoma sinovial primário do esôfago
}

\section{Primary synovial sarcoma of the esophagus}

\author{
Mário Henrique leite de Alencar, ACBC-GO'; Domingos Boldrini, In Memoriam²; Aluysio de Mendonça Costa3; \\ Antônio Talvane Torres de Oliveira, TCBC-SP4; Cyomara Sanches AttaB ${ }^{5}$
}

\section{INTRODUÇÃO}

Sarcoma sinovial (SS) é uma neoplasia maligna de partes moles que ocorre com maior frequência em tecidos periarticulares de extremidades. Este tipo de tumor tem sido relatado também em outros sítios tais como; cabeça, pescoço, mediastino, pleura, retroperitônio e parede abdominal. A ocorrência deste tumor no trato gastrointestinal é extremamente rara. Somente nove casos de SS do esôfago foram relatados na literatura médica até o momento, sendo que este caso clínico é o primeiro diagnosticado no mundo (1979), e o único de que se tem notícia no Brasil.

\section{RELATO DO CASO}

Paciente de 13 anos de idade, do sexo feminino, branca, apresentava queixa de alteração no timbre da voz havia três meses, além de disfagia progressiva necessitando da ingesta concomitante de líquidos para facilitar a deglutição. Referia ainda vômitos pós-prandiais precoces (trinta minutos em média) de alimentos praticamente não digeridos. Tinha história de emagrecimento de $10 \mathrm{~kg}$ nesse mesmo período. Ao exame físico apresentava-se em regular estado geral, desidratada $(2+/ 4+)$ e emagrecida. Exame cervical sem nódulos palpáveis.

A laringoscopia indireta mostrou lesão globosa epitelizada, lisa e posterior de aproximadamente $5 \mathrm{~cm}$ de diâmetro. O tumor rechaçava hemilaringe esquerda e seios piriformes. Tinha exames hematológicos e bioquímicos dentro dos limites da normalidade. A radiografia de tórax foi normal, porém a seriografia de esôfago demonstrou grande falha de enchimento no esôfago proximal (cervical) sugestivo de massa polipóide intraluminal, sendo este o motivo do encaminhamento.

Durante a operação a exposição do esôfago foi feita através de uma cervicotomia pela borda anterior esquerda do músculo esternocleidomastoideo e dissecção cuidadosa das estruturas profundas do pescoço. O esôfago encontrava-se dilatado na região do tumor sem sinais de invasão da adventícia do órgão. Realizada esofagotomia longitudinal na parede ântero-lateral esquerda distante da origem do tumor que estava presa à parede posterior direita do esôfago por um largo pedículo. A tática operatória consistiu na luxação do tumor e ressecção do pedículo com margem, seguido de sutura primária invaginante do local em dois planos.

A paciente evoluiu bem, sem complicações e recebeu alta hospitalar no $4^{\circ}$ dia de pós-operatório. O exame macroscópico da peca revelou massa tumoral de forma cilíndrica medindo 4,0 x 3,0cm, mostrando tecido firme e elástico, finamente trabeculado e permeado por feixes avermelhados que lembravam tecido muscular. Apresentava ainda, cavitação central de 0,4cm, dando saída de material líquido e esbranquiçado.

Histologicamente observou-se neoplasia maligna constituída por tecido de aspecto fibroso, com células fusiformes e figuras anormais de mitose (Figura 1). O tumor desenvolvia-se no tecido conjuntivo e na camada muscular do esôfago e parte dele estava recoberto por mucosa esofagiana que não apresentava alterações significativas. A análise imunoistoquímica das células tumorais

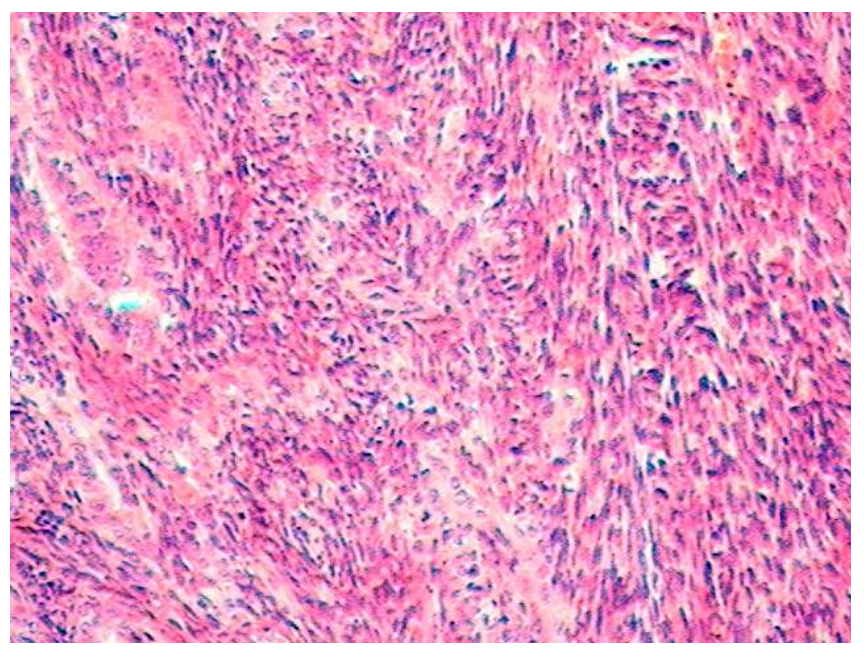

Figura 1 - Sarcoma sinovial de padrão bifásico com presença de células epitélio-glandular e de características fusiformes (HE 100X).

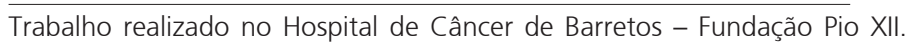

1. Cirurgião Oncológico Hospital de Câncer de Barretos- SP-BR; 2. Chefe do Departamento de Cirurgia de Cabeça e Pescoço do Hospital de Câncer de Barretos; 3. Chefe do Serviço de Cirurgia do Aparelho Digestivo Alto do Hospital de Câncer de Barretos; 4 . Médico Patologista da Fundação Pio XII- Barretos-SP-BR; 5. Médica Especialista em Medicina Nuclear do Hospital de Câncer de Barretos. 
expressavam antígeno de membrana epitelial (EMA), citoqueratina AE1/3, vimentina e proteína S-100 (Figura 2). O diagnóstico anatomopatológico foi de sarcoma sinovial bifásico do esôfago. A paciente não foi submetida à terapia adjuvante e permanece em seguimento ambulatorial com exames de tomografia de tórax, endoscopia digestiva alta, até então, sem evidencias de recidiva tumoral, totalizando um período médio de 27 anos de follow-up.

\section{DISCUSSÃO}

Sarcomas sinoviais compreendem aproximadamente $5 \%$ a $8,5 \%$ de todos os sarcomas de partes moles 2 . Desenvolvem-se mais comumente do tecido conjuntivo próximo de articulações, porém em $10 \%$ dos casos também podem se originar de outros sítios ${ }^{3}$. Nestes casos em que este tecido sinovial está ausente, o tumor passa a se desenvolver de células mesenquimais indiferenciadas. A histologia deste tipo de tumor consiste em um entremeado de células de padrão bifásico com áreas epiteliais contendo

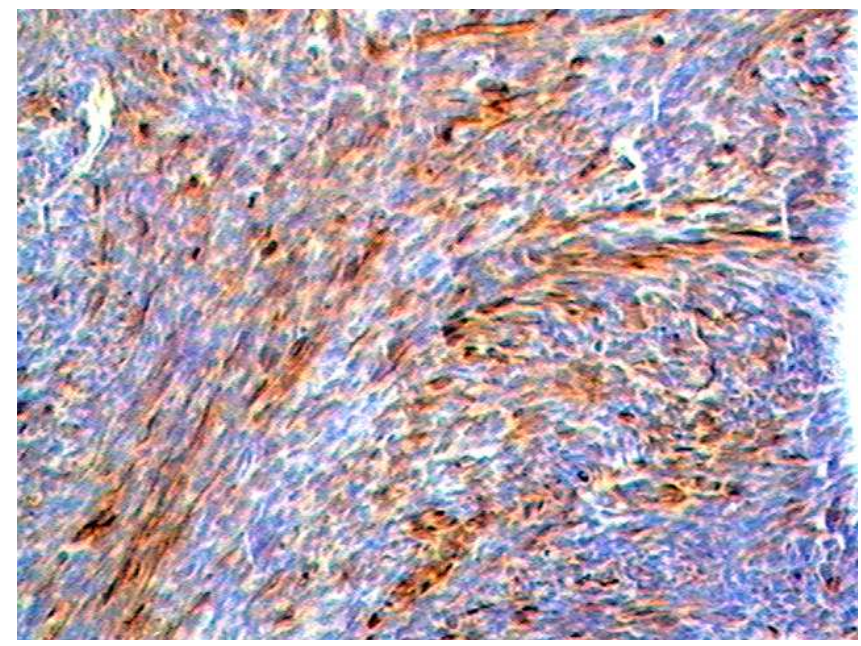

Figura 2 - Aparência histológica pela imunohistoquímica: células espinocelulares apresentam reação evidente para vimentina(aumento de 100x). ácido hialurônico, material mucinoso e elementos sarcomatosos. Pode ser confundido com o carcinosarcoma a não ser pela presença de elementos de carcinoma de células escamosas contidos neste último. Sarcomas do esôfago são excepcionalmente raros, e compreendem cerca de 0,1\% a 1,5\% de todos os tumores do esôfago ${ }^{4}$. Ocorre com maior freqüência como massa polipóide intraluminal, e neste caso, estão incluídas lesões benignas tais como; fibroma, lipoma, hemangioma no diagnóstico diferencial. Os SS apresentamse também com as mesmas características dos sarcomas em geral, porém tem crescimento lento e seus sintomas estão diretamente relacionados com a invasão ou compressão de estruturas adjacentes. A disfagia é o sintoma mais comum. A endoscopia digestiva alta é essencial não só para definir a etiologia do tumor, mas também para planejamento cirúrgico, uma vez que pode demonstrar a natureza pedunculada ou não do tumor. Os SS são tumores de prognóstico incerto.

A taxa de sobrevida em cinco anos varia de $25 \%$ a $65 \%$. A recidiva local ocorre em até $70 \%$ das vezes ${ }^{3}$ e podem metastatizar para o pulmão, linfonodos e medula óssea. Nas séries iniciais, devido às características do tumor expostas anteriormente, o tratamento radical estava indicado (esofagectomia) ${ }^{5}$. Posteriormente, verificou-se que a excisão do tumor pelo pedículo oferecia taxas de sobrevida semelhantes, e atualmente é a conduta mais aceita ${ }^{3}$. Em todos os outros relatos os pacientes foram submetidos à terapia adjuvante com radio e quimioterapia combinados ou não. Em virtude da raridade da doença, e consequentemente pobre casuística, não existe consenso sobre qual a melhor conduta. Acredita-se que a adjuvância com radiação e quimioterapia possa diminuir a taxa de recorrência e metástases, porém essa conduta é controversa ${ }^{3}$. No nosso caso, a paciente apresentava sinais de doença localizada, portanto foi submetida apenas a tratamento cirúrgico sem tratamento complementar. Fato esse digno de nota, uma vez que, apresenta o maior tempo de seguimento dentre todos os casos (o maior foi de $\left.6,5 \operatorname{anos}^{4}\right)$, sem recidiva até então. Esses pacientes devem ter acompanhamento ambulatorial cuidadoso por um longo período.

\section{A}

Synovial sarcomas are uncommon malignant mesenchymal tumors occurring mainly near the joints of the extremities of young adults. Synovial sarcomas are exceedingly rare neoplasms of the digestive tract. We report the first diagnosed case of esophageal synovial sarcoma, highlighting its diagnostic features surgical management and follow-up.

Key words: Neoplasms. Soft tissue neoplasms. Sarcoma. Sarcoma, synovial. Gastrointestinal tract.

\section{REFERÊNCIAS}

1. Butori,C, Hofman V, Attias R, Mouroux J, Pedeutour F, Hofman P. Diagnosis of primary esophageal synovial sarcoma by demonstration of $\mathrm{t}(\mathrm{X} ; 18)$ translocation: a case report. Virchows Arch. 2006;449(2):262-7.

2. Habu S, Okamoto E, Toyosaka A, Nakai Y, Takeuchi M. Synovial sarcoma of the esophagus: report of a case. Surg Today. 1998;28(4):401-4. 
3. Antón-Pacheco J, Cano I, Cuadros J, Vilariño A, Berchi F. Synovial sarcoma of the esophagus. J Pediatr Surg. 1996;31(12):1703-5.

4. Perch SJ, Soffen EM, Whittington R, Brooks JJ. Esophageal sarcomas. J Surg Oncol. 1991;48(3):194-8.

5. Bloch MJ, lozzo RV, Edmunds LH Jr, Brooks JJ. Polypoid synovial sarcoma of the esophagus. Gastroenterology. 1987;92(1):22933.

Recebido em 15/04/2007

Aceito para publicação em 20/05/2007

Conflito de interesse: nenhum

Fonte de financiamento: nenhum

\section{Como citar este artigo:}

Alencar MHL, Boldrini D, Costa AM, Oliveira ATT, Attab CS. Sarcoma sinovial primário do esôfago. Rev Col Bras Cir. [periódico na Internet] 2012; 39(5). Disponível em URL: http://www.scielo.br/rcbc

\section{Endereço para correspondência:}

Mario Henrique Leite de Alencar

E-mail: marinho.alencar@terra.com.br 